\title{
Platelet Signaling in Primary Haemostasis and Arterial Thrombus Formation: Part 2
}

\author{
Rüdiger E. Scharf ${ }^{1,2}$ \\ ${ }^{1}$ Division of Clinical and Experimental Haemostasis, Hemotherapy \\ and Transfusion Medicine, University Blood Center, and Haemophilia \\ Comprehensive Care Center, Institute of Transplantation \\ Diagnostics and Cell Therapeutics, Heinrich Heine University \\ Medical Center, Düsseldorf, Germany \\ 2 Biological Medical Research Center, Heinrich Heine University, \\ Düsseldorf, Germany
}

Hämostaseologie 2018;38:211-222.

\author{
Address for correspondence Professor Rüdiger E. Scharf, MD, PhD, \\ FAHA, Laboratory of Experimental Haemostasis and Thrombosis, \\ Heinrich Heine University, Düsseldorf, Moorenstrasse 5, Building \\ 12.49, D-40225 Düsseldorf, Germany \\ (e-mail: rscharf@uni-duesseldorf.de).
}

\begin{abstract}
Keywords

- platelet signaling

- integrin allb $\beta 3$

- G protein-coupled receptors

- calcium mobilization

\section{Zusammenfassung}

Schlüsselwörter

- Thrombozytäre Signalübertrag

- Integrin allb $\beta 3$

- G-Protein-gekoppelte Rezeptoren

- Kalziummobilisierung

Platelet signal transduction is the focus of this review. While 'classic' platelet signaling through $G$ protein-coupled receptors in response to fluid-phase agonists has been extensively studied, signaling mechanisms linking platelet adhesion receptors such as GPIb-IX-V, GPVI and $\alpha 2 \beta 1$ to the activation of $\alpha$ llb $\beta 3$ are less well established. Moreover, 'non-haemostatic' pathways can also activate platelets in various settings, including platelet-immune or platelet-tumour cell interactions, platelet responses to neutrophil extracellular traps, or stimulation by microbial pathogens. Genetically determined integrin variants can modulate platelet function and increase thrombogenicity. A typical example is the Pro33 (HPA-1b) variant of allb 33 . Recent advances in the genotype-phenotype relation of this prothrombotic variant and its impact on outside-in signaling will be reviewed.

Thrombozytäre Prozesse der Signaltransduktion stehen im Mittelpunkt von Teil II dieser Übersicht. Die 'klassische' Signalübertragung durch G-Protein-gekoppelte Rezeptoren bei Plättchenstimulation mit diffusiblen Agonisten ist intensiv erforscht. Bislang weniger gut untersucht sind hingegen Mechanismen, die Signale thrombozytärer Adhäsionsrezeptoren wie GPIb-IX-V, GPVI und $\alpha 2 \beta 1$ auf $\alpha$ llb $\beta 3$ übertragen und zur Aktivierung dieses Integrins führen. Weiterhin existieren 'nicht-hämostatische' Signalwege, die ebenfalls eine Plättchenaktivierung auslösen können. Hierzu zählen Thrombozyteninteraktionen mit Immunoder Tumorzellen, Reaktionen auf freigesetzte Zellkernkomponenten neutrophiler Granulozyten oder Stimulation durch pathogene Keime. Genetisch determinierte Integrinvarianten können die Plättchenfunktion modulieren und die Thrombogenität erhöhen. Musterbeispiel hierfür ist die Pro33 (HPA-1b)-Variante von allb $\beta 3$. Jüngste Erkenntnisse zur Genotyp-Phänotyp-Beziehung dieser prothrombotischen Rezeptorvariante mit Auswirkungen auf 'Outside-in'-Signalvorgänge werden besprochen.
\end{abstract}

\section{Introduction}

The process of transforming integrin $\alpha$ IIb $\beta 3$ on the platelet plasma membrane into a competent receptor for soluble fibrinogen, von Willebrand factor (VWF), and other fluidphase adhesive proteins is one of the major issues in platelet biology. Conversely, in clinical settings, inhibition of the $\alpha$ IIb $\beta 3$ activity or function is a main target of antiplatelet treatment.

Activation of $\alpha$ IIb $\beta 3$ also represents the 'final common pathway' in platelet responses to a variety of stimuli. Importantly, $\alpha \operatorname{IIb} \beta 3$ is capable of signaling bidirectionally. Thus, received

April 13, 2018

accepted after revision

September 18, 2018 (c) 2018 Georg Thieme Verlag KG Stuttgart · New York
DOI https://doi.org/ 10.1055/s-0038-1675149. ISSN 0720-9355. 
signals to and from the integrin can occur. Regulation of $\alpha$ IIb $\beta 3$ activation is induced from the platelet interior ('inside-out' signaling), while $\alpha$ IIb $\beta 3$, by interacting with the platelet exterior, can control distinct platelet functions ('outside-in' signaling).

\section{Platelet Signaling}

\section{Second Messengers in Platelet Activation}

Cellular activation involves enzymes, substrates, and cofactors engaged in specific protein-protein and protein-lipid interactions. Fundamentals of platelet 'second messengers'a term introduced by E.W. Sutherland (Nobel Prize in 1971) have been known for many years and are, therefore, only briefly summarized. Most soluble agonists induce platelet activation through receptors coupled to distinct heterodimeric guanine $(G)$ nucleotide-binding proteins, commonly designated G protein-coupled receptors (GPCR), mediating inside-out signaling. GPCR engagement triggers activation of phospholipase C (PLC). PLC in turn hydrolyses membraneassociated phosphatidylinositol-4,5-diphosphate, thereby producing second messengers such as inositol-1,4,5-triphos- phate (IP3) and diacylglycerol (DAG). A discussion of the different $G$ protein species ( - Table 1 ), PLC isoforms ( $\beta$ or $\gamma$ ) and signaling pathways downstream of GPCR is beyond the scope of this contribution. The reader is referred to a comprehensive review by Offermanns. ${ }^{1}$

Calcium mobilization. IP3 contributes to $\mathrm{Ca}^{2+}$ mobilization from internal stores, while DAG promotes transmembrane $\mathrm{Ca}^{2+}$ uptake. The net result of these processes is a rise in cytosolic $\mathrm{Ca}^{2+}$ concentration within less than 10 seconds following platelet stimulation by $\alpha$-thrombin or collagen. ${ }^{2}$ Upon platelet stimulation by $\alpha$-thrombin, two distinct PARdependent transient responses have been found: an early, short-lived response (mediated by PAR-1), followed by a more prolonged $\mathrm{Ca}^{2+}$ signal (mediated by PAR-4). ${ }^{3}$ A similar pattern of $\mathrm{Ca}^{2+}$ oscillations was observed during platelet adhesion onto immobilized VWF $\mathrm{VW}^{4}$ and upon ADP- or collagen-induced platelet activation in the presence of high shear. ${ }^{5,6}$ With regard to the synergy between $\alpha 2 \beta 1$ and GPVI, discussed in Part 1 of this review, it has been shown that $\alpha 2 \beta 1$ can induce GPVI-independent $\mathrm{Ca}^{2+}$ signaling; however, longer-lasting $\mathrm{Ca}^{2+}$ oscillations require reinforcement by GPVI through transmembrane ion flux. ${ }^{6}$

Table 1 Receptors, agonists, ligands, and signaling pathways in platelet thrombus formation. Modification of a table taken from Ruggeri $^{35}$; Data adapted from Offermanns. ${ }^{71}$

\begin{tabular}{|c|c|c|c|}
\hline Phase of response & Substrates, agonists, ligands & Receptors & Signaling pathways \\
\hline \multicolumn{4}{|l|}{ Initiation } \\
\hline \multirow[t]{5}{*}{ Tethering and adhesion } & VWF & GPIb-IX-V & PI3K and others \\
\hline & Collagen & GPVI-FcRy, $\alpha 2 \beta 1$ & Syk/PLCy \\
\hline & Fibrinogen, fibrin & $\alpha$ llb $\beta 3$ (resting) & Syk/pp $125^{\text {FAK }}$ \\
\hline & Fibronectin & $\alpha 5 \beta 1$ & Unknown \\
\hline & Laminin & $\alpha 6 \beta 1$ & Unknown \\
\hline \multicolumn{4}{|l|}{ Propagation/Extension } \\
\hline \multirow[t]{5}{*}{ Activation } & $\alpha$-Thrombin & $\begin{array}{l}\text { PAR1, PAR4 } \\
\text { GPIb-IX-V }\end{array}$ & $\begin{array}{l}\mathrm{G}_{\mathrm{q}}, \mathrm{G}_{12}, \mathrm{G}_{\mathrm{i}} / \text { Rho, } \mathrm{PLC} \beta \\
\text { Unknown }\end{array}$ \\
\hline & ADP & $\begin{array}{l}\mathrm{P}_{2} \mathrm{Y}_{1} \\
\mathrm{P} 2 \mathrm{Y}_{12}\end{array}$ & $\begin{array}{l}\mathrm{G}_{\mathrm{q}}\left(\mathrm{G}_{12}\right) / \text { Rho, } \mathrm{PLC} \beta \\
\left(\mathrm{G}_{\mathrm{i} 2} / \text { adenylyl cyclase }\right.\end{array}$ \\
\hline & Thromboxane $A_{2}$ & $\mathrm{TP} \alpha / \beta$ & $\mathrm{G}_{\mathrm{q}}\left(\mathrm{G}_{12}\right) /$ Rho, $\mathrm{PLC} \beta$ \\
\hline & Epinephrine & $\alpha_{2 A}$-adrenergic & $\left(\mathrm{G}_{2} /\right.$ adenylyl cyclase \\
\hline & Serotonin & $5-\mathrm{HT} 2 \mathrm{~A}$ & $\mathrm{G}_{\mathrm{g}} ?$ \\
\hline Aggregation & Fibrinogen, VWF, fibronectin & $\alpha$ llb $\beta 3$ (activated) & SFK, SHC \\
\hline \multicolumn{4}{|l|}{ Stabilization } \\
\hline & P-selectin & PSGL-1, GPIb-IX-V, others? & Unknown \\
\hline & Ephrin & EPH kinases & Lyn, Fyn \\
\hline & CD40 ligand & $\alpha$ llb $\beta 3$ (activated) & Unknown \\
\hline & GAS6 & $\overline{A X L}$ & PI3K, PLCY \\
\hline
\end{tabular}

Abbreviations: AXL, AXL receptor tyrosine kinase; EPH, ephrin receptor; Fyn, shrinkage-activated tyrosine kinase; GAS6, growth arrest-specific 6; GP, glycoprotein; 5-HT2A, serotonin receptor; Lyn, tyrosine kinase; PAR: protease-activated receptor(s); PECAM: platelet-endothelial cell adhesion molecule; PI3K, phosphatidylinositol 3-kinase; PLC, phospholipase C; PSGL-1, P-selectin glycoprotein ligand; Rho (Ras homology): distinct family of GTPases belonging to the Ras superfamily; SFK, Src family of tyrosine kinases; SHC, Src homology domain-containing transforming protein C, an adaptor molecule; Syk, tyrosine kinase; TP, thromboxane receptor; VWF, von Willebrand factor.

Source: Modification of a table taken from Ruggeri. ${ }^{57}$ Data adapted from Offermanns. ${ }^{1}$ 
Effects of calcium mobilization. Apart from triggering aggregation, the increase in cytosolic $\mathrm{Ca}^{2+}$ concentration amplifies or regulates many functions and pathways in platelets. ${ }^{2}$ For example, $\mathrm{Ca}^{2+}$ causes a p38 MAP (mitogenactivated protein) kinase-dependent activation of phospholipase $A_{2}$, which hydrolyzes membrane phospholipids, leading to the production of arachidonic acid (AA) and $\mathrm{TXA}_{2}$ synthesis. The conversion of AA into $\mathrm{TXA}_{2}$ is mediated by cyclooxygenase- 1 and thromboxane synthase. TXA 2 functions as a positive feedback mediator during platelet activation. Interestingly, platelet responses to $\mathrm{TXA}_{2}$ and also to $\alpha$ thrombin, at low or intermediate concentrations, are reduced in the absence of ADP receptors (for review, see the article by Offermanns ${ }^{1}$ ). This observation underlines the importance of ADP as a positive feedback agonist that amplifies the responses by other stimuli, thereby inducing sustained platelet activation.

Conversely, suppression of $\mathrm{Ca}^{2+}$ mobilization by cyclic nucleotides can stabilize platelets in the resting state. An increase in intracellular cyclic adenosine monophosphate (cAMP) and cyclic guanosine monophosphate (cGMP) levels is achieved in either way, by stimulating their synthesis (via cyclic adenylate/guanylate cyclase) or by inhibiting their degradation (via phosphodiesterase, PDE). $\mathrm{PGI}_{2}$ and NO (see - Fig. 1 in Part 1) inhibit platelet activation using option one, while dipyridamole and several other agents are PDE inhibitors. ${ }^{7}$ Negative regulation of platelet activity by cAMP and cGMP and, most importantly, negative control of $\alpha \mathrm{IIb} \beta$ involve the protein kinases A and G (PKA, PKG). Their substrates are the IP3 receptor and certain signaling

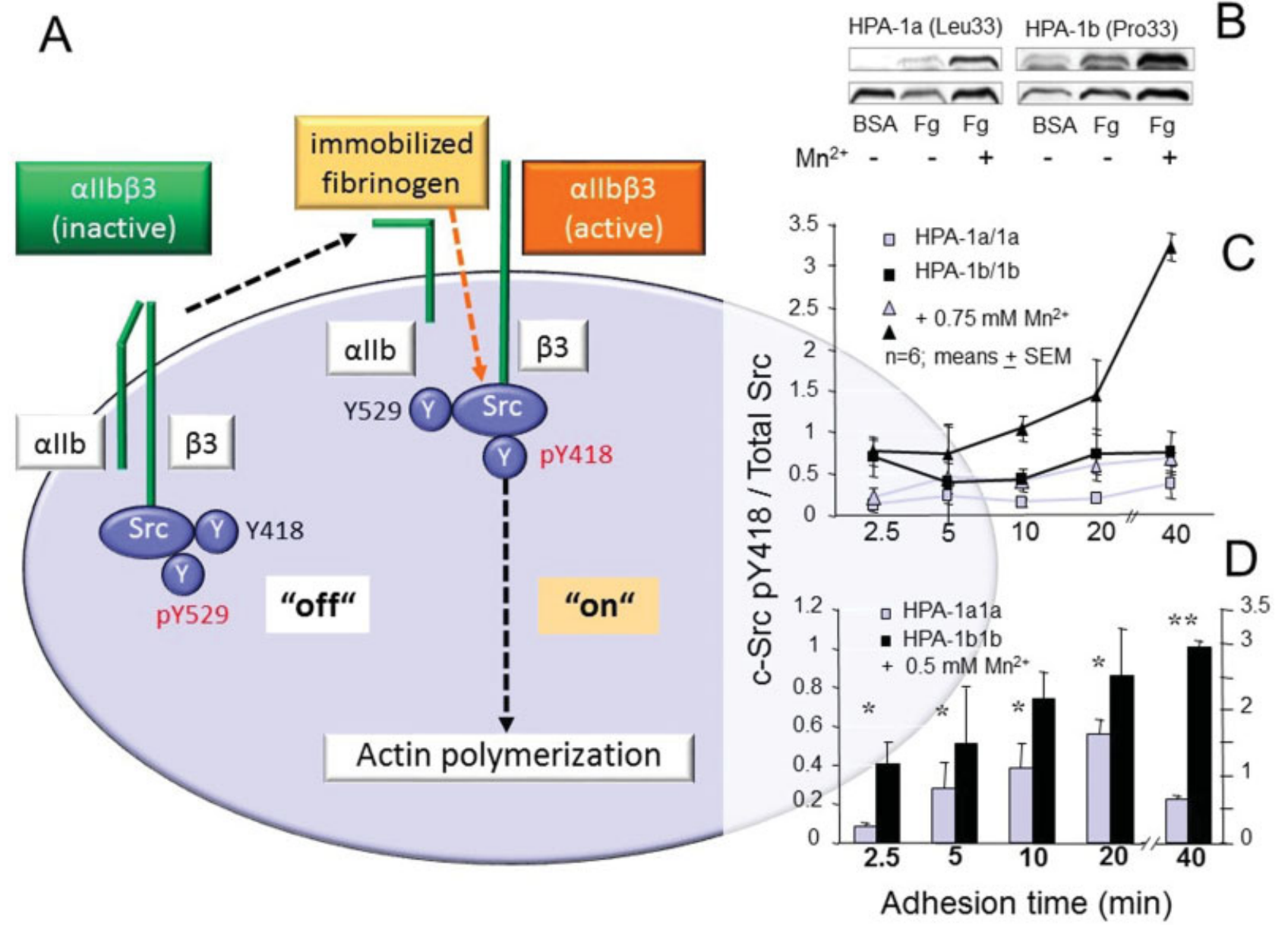

Fig. 1 c-Src-mediated outside-in signaling in HPA-1 variants of $\alpha$ llb $\beta 3$ upon platelet adhesion. c-Src, a tyrosine kinase, is bound to the $\beta 3$-subunit and interacts co-ordinately with two other tyrosine kinases (Csk and Syk) that are associated with $\alpha$ llb $\beta 3$. c-Src is essential for outside-in signaling upon ligand binding and microclustering of the receptor. (A) Schematic representation of c-Src activation. In the inactive state, c-Src is maintained in a 'clamped' conformation through intramolecular interactions and a phosphotyrosine motif at Tyr525 (pY525), indicated on the left. Upon ligation of allb 33 by immobilized fibrinogen, c-Src undergoes a conformational change with dephosphorylation of Tyr525 and trans-autophosphorylation of Tyr418 (pY418) in the activation loop. c-Src is now 'unclamped' and fully active to phosphorylate downstream effectors implicated in signaling to the actin cytoskeleton (-Fig. 2). (B) through (D) Activity of c-Src pY418 in platelets adhering onto fibrinogen (Fg), examining both $\alpha$ llb $\beta 3$ isoforms, HPA-1a (Leu33) and HPA-1b (Pro33). (B) Western blots are probed with specific antibodies to c-Src pY418 (upper panel), total c-Src (lower panel), or c-Src pY525 (not shown), quantified densitometrically, and expressed as ratio of c-Src p418 to total c-Src. Representative results of six separate experiments. Washed platelets that were allowed to adhere onto $\mathrm{Fg}(100 \mu \mathrm{g} / \mathrm{mL})$ in the absence or presence of added $\mathrm{Mn}{ }^{2+}$. (C) Adherent platelets homozygous for HPA-1b (closed squares in the absence of $\mathrm{Mn}^{2+}$ ) exhibit significantly enhanced c-Src pY418 activity as early as 2.5 minutes of incubation time in comparison to HPA-1a platelets (open squares). Throughout, addition of Mn ${ }^{2+}(0.5$ or 0.75 mM) increases c-Src pY418 activity substantially more in HPA-1b (closed triangles) than in HPA-1a platelets (open triangles) and (D) peaks at prolonged incubation times. $p<0.05$, ${ }^{* *} p<0.01$ (unpaired $t$-test). 
molecules, which, upon phosphorylation at distinct sites, either attenuate platelet responses or maintain platelets in the resting state. ${ }^{8}$

\section{Integrin 'Inside-Out' versus 'Outside-In' Signaling} Integrins display bidirectional signal transduction. ${ }^{9}$ Their regulation can be divided into 'inside-out' and 'outside-in' signaling. ${ }^{8-12}$ The distinction has primarily been made for experimental reasons.

In platelets, inside-out signal transduction denotes responses that are typically initiated by binding of one or more agonists (such as $\alpha$-thrombin, TXA $\mathrm{A}_{2}$, ADP, or epinephrine) to cognate agonist receptors (GPCR) on the platelet surface. This interaction in turn stimulates signaling pathways that eventually result in the activation of $\alpha \operatorname{IIb} \beta 3$, characterized by the conversion from a low-affinity into a high-affinity state and the ability to bind soluble macromolecular ligands. Hence, in this signaling mode, $\alpha \operatorname{IIb} \beta 3$ is activated by stimulation from the platelet interior.

Outside-in signal transduction denotes responses initiated by adhesive ligand binding to (and clustering of) the integrin leading to the generation of inward-directed signals that promote further platelet responses ('post-occupancy' or 'post-ligand' events). The responses regulated by $\alpha I I b \beta 3$ include activation of additional integrins, cytoskeletal rearrangements, platelet secretion, and development of platelet procoagulant activity. ${ }^{11}$ Hence, in this mode, 'contact'- or 'anchorage'-dependent signaling from the outside induces $\alpha$ IIb $\beta 3$ activation. This process requires coordination with signals emanating from other plasma membrane receptors, typically from GPCR. ${ }^{10}$

Importantly, apart from $\alpha \operatorname{IIb} \beta 3$, certain adhesion receptors, notably GPIb-IX-V, GPVI, and $\alpha 2 \beta 1$, can generate signals and trigger activation, when ligated ('occupied and/or clustered') by ECM ligands. ${ }^{8}$ The mode of how multiple key players orchestrate $\alpha \mathrm{IIb} \beta 3$ outside-in signaling has recently been discussed in a comprehensive review, summarizing major advances in this field. ${ }^{13}$

\section{Signaling Mechanisms Linking Platelet Adhesion Receptors to $\alpha$ Ilb $\beta 3$ Activation}

The 'final common pathway' of the different signaling cascades in platelets is the activation of $\alpha \operatorname{IIb} \beta 3$, the principal receptor for stable adhesion and aggregation. In recent years, major progress has been made in understanding the complex interactions, by which important biological functions of integrins (including the change in ligand-binding properties) are regulated downstream of GPCRs and platelet adhesion receptors. ${ }^{14}$

Signaling through GPIb-IX-V. The effector mechanisms, through which signaling downstream of VWF-A1 binding to GPIb-IX-V operates, are incompletely explored at present. This is mainly due to the impossibleness to separate adhesive and signaling functions of the receptor. However, several major advances have been made.

First, a mechanosensitive domain in GPIb $\alpha$ has recently been identified. ${ }^{15}$ Consequently, it is postulated that the
VWF-A1 link to GPIb $\alpha$ represents a sensor of biomechanical force that in turn, through mechanotransduction, could provide signals to conform the platelet activation response to the haemodynamic conditions of a growing thrombus. ${ }^{16}$ Second, indirect evidence suggests that clustering of GPIb-IX$\mathrm{V}$ complexes can induce upregulation of the adhesive properties of $\alpha$ IIb $\beta 3$ though VWF-dependent signaling, thereby promoting thrombus formation. ${ }^{17}$ Third, Ruggeri's and Shattil's groups have shown that dimeric VWF-A1 can induce signaling through GPIb-IX-V followed by subsequent activation of $\alpha \mathrm{IIb} \beta 3 .{ }^{18}$ Importantly, this response is independent of other receptors and involves sequential actions of c-Srcrelated tyrosine kinases, $\mathrm{Ca}^{2+}$ oscillations and PI3K/PKC (phosphatidylinositol 3-kinase/protein kinase C).

Fourth, GPIb-IX-V can associate with Fc receptors (FcR), FcR $\gamma$-chain and FcrRIIa, containing an immuno-receptor tyrosine-based activation motif (ITAM) ${ }^{19}$ In analogy to other ITAM-coupled receptors (such as GPVI ${ }^{14}$ ), the observation supports the hypothesis that a cross-linking mechanism may be involved in GPIb-IX-V-induced signaling. ${ }^{16} \mathrm{~A}$ key feature in this scenario is tyrosine phosphorylation of the ITAM sequence by a c-Src family tyrosine kinase, leading to recruitment and auto-phosphorylation of a Syk family kinase. ${ }^{19}$ Syk initiates a signaling cascade that culminates in the activation of second messenger generating enzymes (PI3K and PKC) with production of IP3, as discussed. Subsequent binding of IP3 to its receptor on the dense tubular system mobilizes $\mathrm{Ca}^{2+}$ from internal stores and also induces $\mathrm{Ca}^{2+}$ uptake from the external milieu. The resulting transient $\mathrm{Ca}^{2+}$ oscillations in response to ligation of GPI $\alpha$ by VWF-A1 were recently reviewed in detail by Ruggeri and Mendolicchio. ${ }^{16}$

Signaling through GPVI. This collagen receptor, a member of the immunoglobulin superfamily, is exclusively expressed in megakaryocytes and platelets. ${ }^{20} \mathrm{GPVI}$ undergoes a noncovalent association with the FCR $\gamma$-chain that contains the ITAM-bearing signal transducing domain. ${ }^{19}$ Upon binding to collagen, cross-linking of GPVI induces interaction of the FCR $\gamma$-chain with the c-Src family tyrosine kinases Fyn and Lyn, resulting in tyrosine phosphorylation of the ITAM. ${ }^{19}$ The subsequent signaling pathway is identical to that described earlier. Nieswandt and Watson have extensively studied the function and signaling of GPVI both in men and mice. For details, the reader is referred to comprehensive reviews by these investigators. ${ }^{14,21,22}$

Signaling through integrin $\alpha 2 \beta 1$. Ligation of $\alpha 2 \beta 1$ by collagen contributes to platelet activation in two ways, indirectly by reinforcing GPVI-collagen interactions and directly by a series of outside-in signaling events that involve c-Src, Syk, SLP-76 (a haematopoietic member of the $76 \mathrm{kDa}$ adapter protein family) ${ }^{23}$ and PLC $2 .^{21}$ Adaptor proteins (APs) are structural and functional 'linker' molecules; they lack intrinsic effector functions but contain distinct modular domains, which mediate protein-protein interactions. APs serve as scaffolds, around which effectors and their substrates are assembled into signaling complexes. Of note, the two platelet collagen receptors, GPVI and $\alpha 2 \beta 1$, although structurally unrelated, are sharing crucial molecules in their downstream signal transduction. 
Signaling through integrin $\alpha I I b \beta 3$. Among the five integrins ( $\alpha \mathrm{IIb} \beta 3, \alpha v \beta 3, \alpha 2 \beta 1, \alpha 5 \beta 1, \alpha 6 \beta 1$ ) expressed in platelets, $\alpha \operatorname{IIb} \beta 3$ is, with approximately 80,000 copies on the surface of resting platelets, by far the most dominant receptor, both qualitatively and quantitatively ( $>98 \%$ compared with the other platelet integrins). The central role of $\alpha \operatorname{Ilb} \beta 3$ has been subject to several excellent reviews, ${ }^{8,10-13,24,25}$ some of which discuss inside-out signaling pathways downstream of agonist receptors in detail. In fact, this contribution is focused on outside-in signal transduction events.

aIIbß3-mediated outside-in signaling is initiated by specific trans-auto-phosphorylation of the tyrosine kinase c-Src bound via its SH3 domain to the $\beta 3$ cytoplasmic tail of active $\alpha \operatorname{IIb} \beta 3^{26}$ ( - Fig.1). Activation of c-Src is tightly regulated. In its resting state, $\mathrm{c}-\mathrm{Src}$ is under the control of Csk, another tyrosine kinase that is also associated with $\alpha$ IIb $\beta 3$. Csk negatively regulates c-Src activity by phosphorylating Tyr529. Adhesion of $\alpha$ IIb $\beta 3$ to immobilized fibrinogen causes Csk to dissociate from $\alpha \mathrm{Ilb} \beta 3$, concomitant with dephosphorylation of Src Tyr529 and phosphorylation of the c-Src activation loop at Tyr418. ${ }^{27}$ As indicated by 'off' and 'on' (-Fig. 1A), Csk and c-Src function as molecular switches in this trans-autophosphorylation. A third tyrosine kinase, Syk, involved in this regulation and subsequent signaling, associates with $\alpha \mathrm{IIb} \beta 3$ after fibrinogen binding (receptor 'occupancy').

Upon phosphorylation of the Tyr 418 motif, c-Src induces Syk-mediated activation of Vav1 followed by GTP loading on Cdc42 and Rac1 (-Fig. 2, inset), which drive lamellipodia formation and platelet spreading. ${ }^{28}$ Vav1 belongs to a family of proteins that act as guanine nucleotide exchange factors for small $G$ proteins of the Rho/Rac family. Cdc42 and Rac1

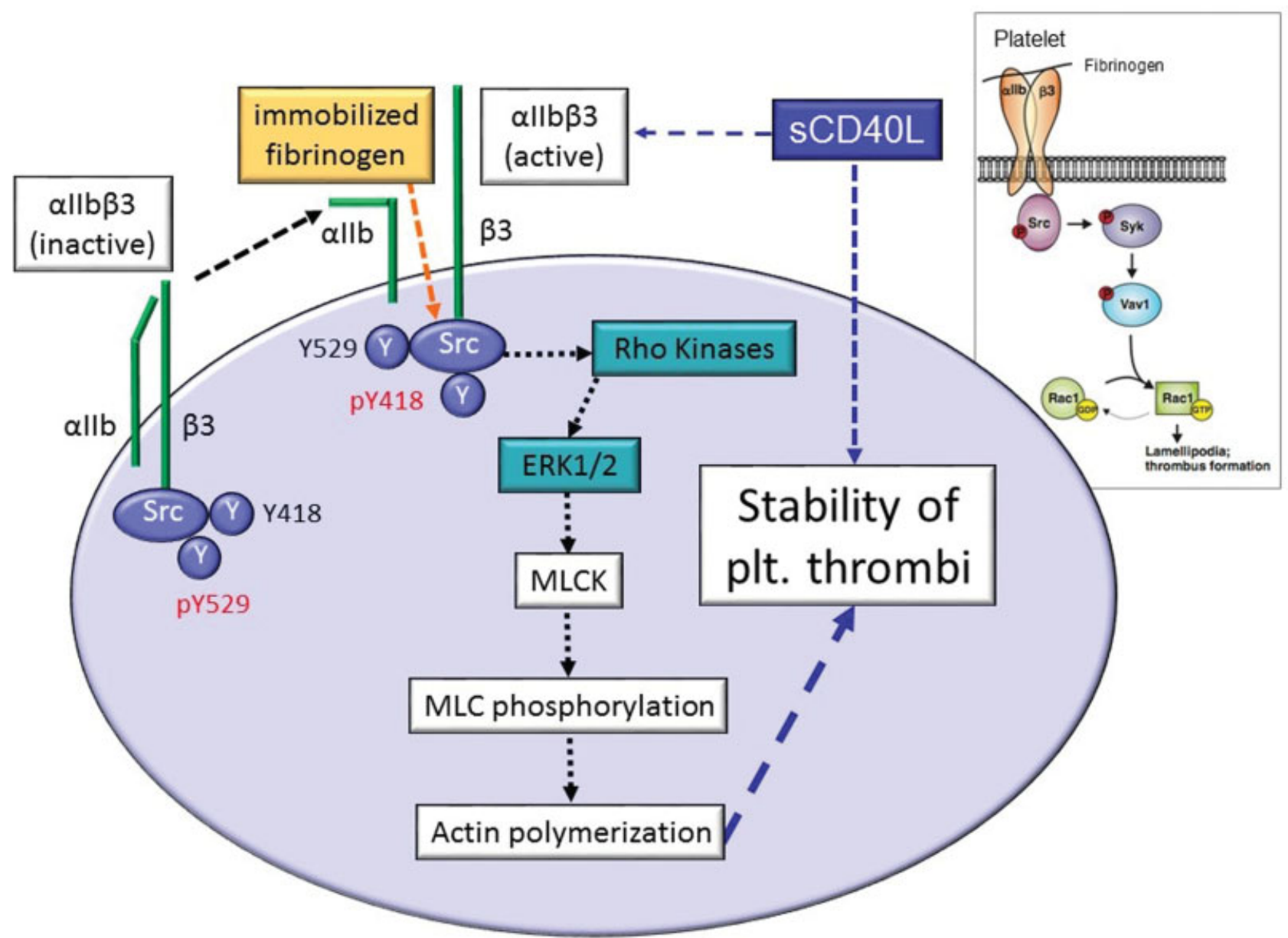

Fig. 2 Effectors of allbß3-mediated outside-in signaling downstream of c-Src. Simplified overview of the c-Src/Rho/ERK1/ERK2 pathway transmitting signals to the actin cytoskeleton. SCD40L acts by the same route, contributing to the aggregate/thrombus stability (see Part 1). In platelets, the c-Src family of kinases (SFKs) phosphorylates a plethora of signaling and/or membrane-associated molecules, of which only a few are depicted here. Members of the Rho family of GTP-binding proteins (also designated Rho GTPases) are master regulators of the platelet function. Thus, Rho GTPases operate as molecular switches in the transduction and amplification of signals from surface receptors to the signaling pathways that drive and regulate platelet function. ${ }^{63}$ Inset: Among the Rho GTPases, Rac1 is one of the key regulators of the platelet actin cytoskeleton. Rac1 is activated by Vav1 (a guanine nucleotide exchange factor), acts via the MAP kinase cascade and contributes essentially toward the controlling of spreading, aggregation, secretion and thrombus formation. Two MAP kinases, ERK1 (p44) and ERK2 (p42), are involved in signal transmission to the cytoskeleton. The ERK substrate, MLC kinase, is directly phosphorylated by ERK2. Upon platelet activation, coordinated inhibition of the MLC phosphatase and activation of MLC kinase are required to promote platelet secretion. FAK (see - Fig. 5) is another important substrate of SFKs downstream of $\alpha$ llb $\beta 3$ in response to receptor clustering. ${ }^{25}$ Abbreviations: ERK, extracellular signal-regulated kinases; FAK, focal adhesion kinase; MAP, mitogen-activated protein; MLC, myosin light chain; SCD40L, soluble CD40 ligand; SFK, Src family (tyrosine) kinases. Inset: modification of a figure taken from Huveneers and Danen. ${ }^{64}$ 
are members of the Rho/Rac family. Importantly, these GTPases are GTP-binding proteins, which cycle between inactive GDP-bound and active GTP-bound states and thus function as molecular switches. Several lines of evidence exist that RhoA activity is required to maintain stable interactions of $\alpha \mathrm{IIb} \beta 3$ with ECM components under highshear conditions. ${ }^{29}$ Subsequent steps in this signaling cascade involve several molecular adapter proteins (SLP-76; ADAP, adhesion and degranulation-promoting protein; and $\mathrm{c}-\mathrm{Cb} 1)$ as well as PLCY2, resulting in platelet spreading on immobilized fibrinogen. Thereby, c-Src forms a complex with tyrosine-phosphorylated focal adhesion kinase (FAK). Other substrates implicated in signaling to the actin cytoskeleton will be discussed in the section on integrin variants.

It has become evident that this pathway initiated by direct interaction of $\alpha \mathrm{IIb} \beta 3$ with c-Src is crucial for normal haemostasis. Thus, a $\beta 3$-integrin mutant that can bind to its ligand but is impaired in outside-in signaling fails to rescue the $\beta 3$-integrin knockout phenotype in mice, which is characterized by severe bleeding, similar to consequences of mutations in the ITGB3 gene in humans, causing Glanzmann thrombasthenia. ${ }^{30}$

\section{Platelet Signaling through G Protein- Coupled Receptors}

As outlined in the Part 1 of this series, initial adhesion of platelets to vascular lesions is largely independent of soluble agonists, most of which induce $G$ protein-mediated signaling. By contrast, subsequent recruitment of flowing platelets into a growing thrombus requires diffusible excitatory mediators. The same holds true for adherent platelets to induce full activation, irreversible adhesion, and stable platelet-toplatelet cohesion/aggregation. In addition to thrombin, the second wave of platelet stimulation is caused by dense granule secretion of ADP and serotonin along with the synthesis and release of $\mathrm{TXA}_{2}$.

Three major signaling pathways induce platelet activation through GPCR. Initiation is achieved by activating the $G$ proteins $G_{q}, G_{12 / 13}$, and $G_{i}$ (-Table 1). Downstream events by this inside-out signaling process involve a wide array of molecular species, including kinases, phosphatases and adaptor proteins. The concerted action of multiple agonist receptors and multiple routes of activation ensures that initial responses to individual agonists are amplified to support irreversible platelet aggregation. For further information, the reader is referred to comprehensive reviews. ${ }^{1,14}$

\section{Platelet Agonists Functioning through 'Non- haemostatic Pathways'}

Platelets do not function exclusively in haemostasis or induce thrombotic complications in atherosclerosis. It is becoming increasingly evident that platelets are actively involved in inflammatory processes, host defence, innate and adaptive immunity, and cancer progression. ${ }^{31,32}$ Thus, platelets can actively contribute to communication with and/or co-regulation of multiple cell types. Those interactions may result in mutual cellular activation, whereby platelets often utilize (or 'misuse') their adhesion receptors that normally function in haemostasis.

Platelet-immune cell interactions are manifold. For example, GPIb $\alpha$ on matrix-adherent platelets facilitates recruitment of neutrophils through binding to leukocyte integrin $\alpha \mathrm{M} \beta 2$ (Mac-1). ${ }^{31}$ Microparticles bearing Mac-1 and derived from stimulated neutrophils can bind to platelets via GPIb $\alpha$ and promote platelet P-selectin expression and $\alpha$ IIb $\beta 3$ activation. ${ }^{33}$ Stimulated platelets secrete several important cyto- and chemokines ${ }^{34}$ and promote activation of neutrophils or cause activation of dendritic cells, thereby increasing antigen presentation to $\mathrm{T}$ cells.

Neutrophil extracellular traps (NETs) are another example of immune cell-platelet interactions. NETs are composed of DNA, histones and serine proteases and are part of the antibacterial defence mechanism ${ }^{35}$ but can also promote tumour growth and metastasis. ${ }^{36}$ NETs form a meshwork ('NETosis'), thereby providing a scaffold and stimulus for the binding of platelets and thrombus growth. ${ }^{37}$ Conversely, host DNases, degrading NETs, protect from thrombotic vascular occlusions and organ failure in septicemia. ${ }^{38}$

Platelets may directly interact with histones, in part through platelet toll-like receptors, TLR2 and TLR4. ${ }^{39}$ Moreover, several histones can act as substrates for platelet adhesion and spreading or stimulate fibrinogen binding to $\alpha$ IIb $\beta 3$. Platelet activation triggered by histones is mediated by ERK (extracellular signal-regulated kinases) via the PI3K/ AKT pathway (PI3K, phosphatidylinositol 3-kinase; AKT, protein kinase B) and the p38 MAPK pathway (p38, belonging to the MAP kinases [MAPKs]). ${ }^{40}$ Among other examples, these multifaceted interactions illustrate that platelets are involved in many processes beyond haemostasis.

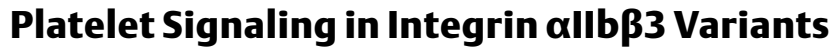

Platelet membrane GPs are highly polymorphic. This also holds true for $\alpha$ IIb $\beta 3$ and $\alpha 2 \beta 1$. The human platelet antigen-1 (HPA-1) polymorphism in $\alpha$ IIb $\beta 3$ arises from a Leu $\rightarrow$ Pro exchange at residue in the $\beta 3$-subunit, resulting in Leu33 (HPA-1a) or Pro33 (HPA-1b) isoforms (-Fig. 3).

\section{Impact of the HPA-1 Polymorphism on allbß3}

Clinical association studies, using a case-only design, have shown that patients with coronary artery disease (CAD) who are carriers of the HPA-1b allele experience their myocardial infarction five years earlier in life than CAD patients who are HPA-1b negative ${ }^{41,42}$ and that, upon saphenous-vein coronary bypass grafting, HPA-1b is a hereditary risk factor for bypass occlusion, myocardial infarction, or early death $(<30$ days) after bypass surgery. ${ }^{43}$ These results suggest that the Leu $\rightarrow$ Pro exchange may modulate functional properties of $\alpha I I b \beta 3$, resulting in a prothrombotic integrin variant. ${ }^{44}$ Indeed, in subsequent experiments under flow-dynamic conditions, it was documented that Pro33 (HPA-1b) platelets and $\alpha$ IIbß3 (Pro33)-transfected cells display a prothrombotic 


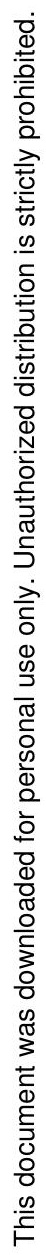



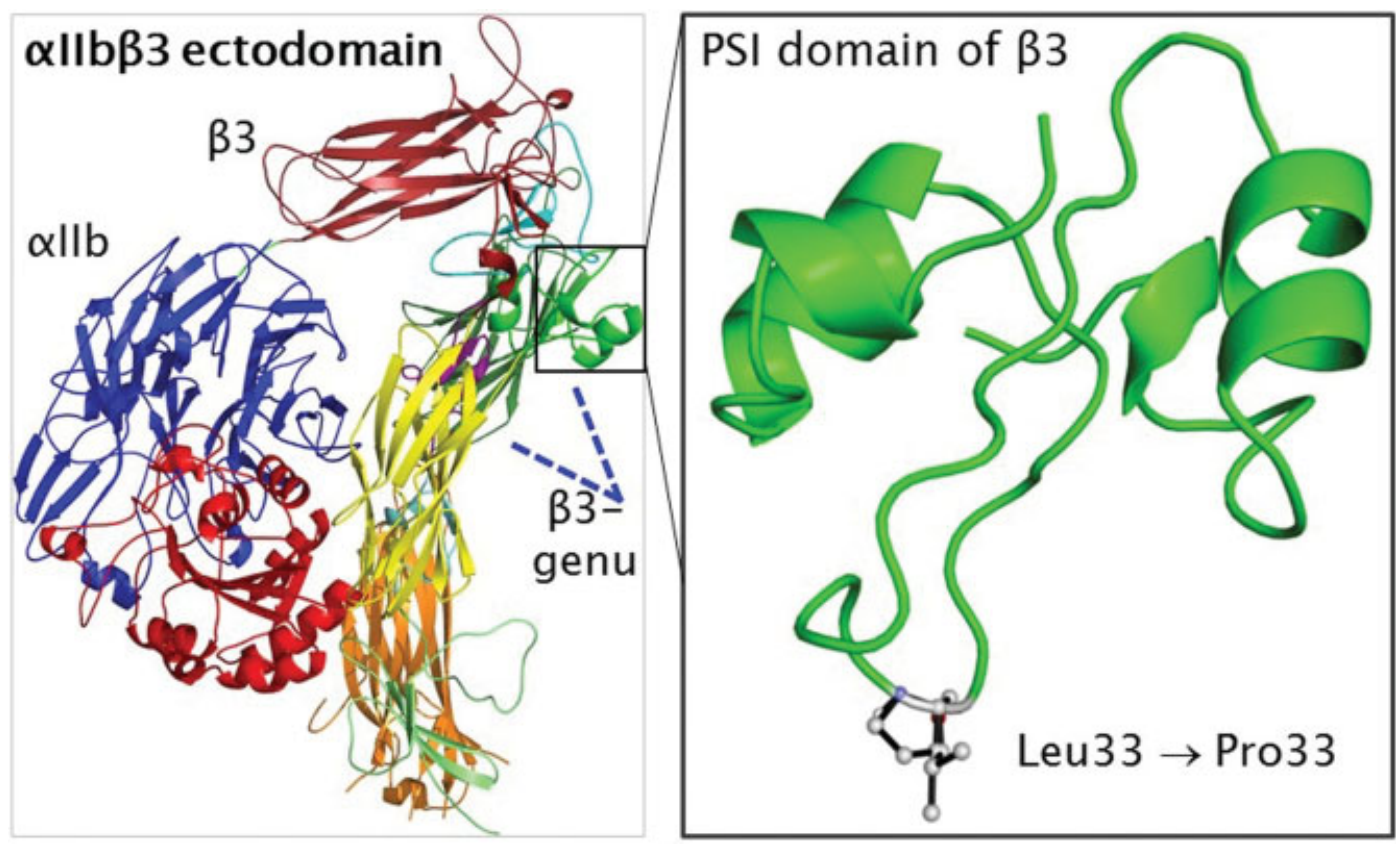

Fig. 3 Model of $\alpha$ llb $\beta 3$ and location of the Leu33 $\rightarrow$ Pro33 exchange (HPA-1 polymorphism). Depicted are the extracellular domains of the $\alpha$ - and $\beta$-subunits in the bent conformation of the integrin. The 'head' of the receptor is formed by the $\beta$-propeller of the $\alpha$ llb-subunit (shown in blue) and the $\beta$ A domain of the $\beta 3$ subunit (shown in magenta); the 'legs' are formed by the thigh and calf domains ( $\alpha$ llb subunit) and four EGF domains together with the $\beta$-tail domain ( $\beta 3$-subunit). The PSI (plexin-semaphorin-integrin, shown in green) domain with the adjacent hybrid and EGF-1 domains are part of the $\beta 3$ 'genu' (indicated by blue dashed lines). The $\beta 3$ genu is of particular interest in integrin activation. The EGF domains (EGF1 through EGF4) are shown in purple, yellow, light blue or ochre, respectively. Enlargement: location of the Leu $\rightarrow$ Pro exchange at residue 33 in the genu of the $\beta 3$-subunit ecto domain. Of note, although located $>80 \AA$ away from extracellular binding sites and $>90 \AA$ away from the transmembrane domains, the Pro33 substitution has a strong impact on the structural and functional stability of the entire molecule. The dynamic conformational equilibrium of $\alpha \mathrm{llb} \beta 3$ is allosterically shifted to a structural state that is closer to the active conformation. Thus, the fully active state of $\alpha$ llb $\beta 3$ is promoted, thereby fostering the prothrombotic phenotype of Pro33 (HPA-1b) platelets. ${ }^{50}$

phenotype, as characterized by increased adhesion activity, ${ }^{45,46}$ increased resistance of adherent transfectants to high shear, ${ }^{47,48}$ increased aggregate/thrombus formation ${ }^{49,50}$ and increased outside-in signaling. ${ }^{51,52}$

Recently, the molecular nature of this prothrombotic integrin variant was elucidated. Using Förster's resonance energy transfer and molecular dynamics simulations, evidence was provided that the Leu $\rightarrow$ Pro exchange weakens interdomain interactions at the $\beta 3$-subunit genu located between the PSI and EGF-1/EGF-2 domains (-Fig. 3). This effect alters the structural dynamics of $\alpha \mathrm{IIb} \beta 3$ to a more bent and splayed state, which results in a conformation that is closer to the active one, promoting the fully active state and fostering the prothrombotic phenotype of Pro33 platelets. ${ }^{50}$

\section{Impact of the HPA-1 Polymorphism on c-Src Activity}

Platelet adhesion onto immobilized fibrinogen causes a prompt activation of c-Src ( - Fig. 1B). As less than 3 minutes of incubation, adherent platelets homozygous for HPA-1b (Pro33) exhibit a significantly enhanced c-Src activity when compared with HPA-1a (Leu33) platelets. Prolonged incubation has no effect on this difference between the two isoforms of $\alpha I I b \beta 3$, both of which display a nearly constant phosphorylation rate (-Fig.1C). By contrast, pretreatment of platelets with $\mathrm{Mn}^{2+}$, in a dose-dependent manner (data not shown), largely enhances the c-Src activity of the Pro33 variant but causes a significant lower increase in phosphorylating the specific Tyr418 motif of the Leu33 isoform (-Fig. 1C, D).

Metal ions are required for the binding of fibrinogen and VWF to $\beta 3$ integrins, ${ }^{12}$ and using $\mathrm{Mn}^{2+}$ is an established experimental tool to induce an active 'unbent' conformation of $\alpha$ IIb $\beta 3$ by acting via three metal ion binding sites in the $\beta 3$ subunit, notably MIDAS (metal ion-dependent adhesion site). ${ }^{53}$ Based on the molecular dynamics analysis, demonstrating an allosteric shift of the Pro33 variant toward an active integrin, ${ }^{50}$ it is now possible to provide a concise explanation for the observed differences in c-Src activation between the two isoforms of $\alpha$ IIb $\beta 3$.

\section{Impact of the HPA-1 Polymorphism on ERK1/ ERK2 Activity}

Among the mitogen-activated protein (MAP) kinases, two extracellular signal-regulated kinases, ERK1 (p44) and ERK2 (p42), are involved in signal transmission to the cytoskeleton, both of which are substrates of upstream Rho GTPases (-Fig. 2, inset). Activation of ERK1/ERK2 is induced by tyrosine/threonine (Tyr/Thr) phosphorylation. In comparison to Leu33, adherent Pro33 platelets display substantially greater ERK2 activation (-Fig. 4). Protein phosphatase-1 (PP1), a potent and selective inhibitor of the c-Src family 


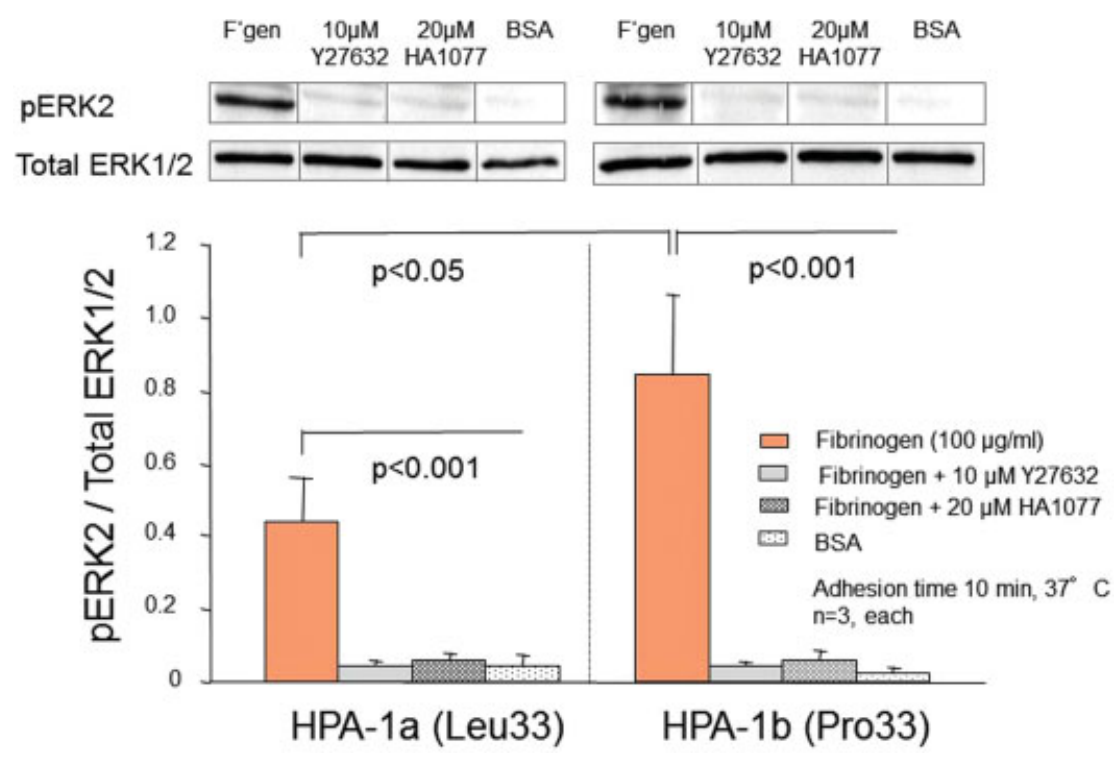

Fig. 4 ERK2 activity and effect of Rho kinase inhibitors on adherent platelets. The two extracellular signal-regulated kinases, ERK1 and ERK2, belong to the mitogen-activated protein kinases (MAPKs), a family of serine/threonine kinases activated by diverse extracellular stimuli. Washed platelets homozygous for either genotype of $\alpha$ llb $\beta 3$ are left in suspension in a BSA-coated dish (control) or tested following adhesion onto immobilized fibrinogen in the absence or presence of potent Rho kinase inhibitors, Y27632 or HA1077. Both agents selectively target the Rhoassociated protein kinase ROCK. Western blots are probed with a specific anti-phospho-antibody to pERK2 or an antibody to ERK1/2 and quantified by densitometry; results are expressed as ratio of ERK2 to total ERK. Pro33 platelets display a twofold higher ERK2 phosphorylation rate than Leu33 platelets. Rho kinase inhibitors abrogate pERK activity in either isoform. Experimental conditions: fibrinogen $(100 \mu \mathrm{g} / \mathrm{mL})$; incubation at $37^{\circ} \mathrm{C}$; adhesion time of 10 minutes; results (mean \pm SEM) of three experiments in each setting.

kinases (SFK), entirely blocks activation of ERK2 (data not shown), providing indirect evidence that the ERK2 Tyr/Thr phosphorylation is mediated through a c-Src tyrosine kinases pathway. ${ }^{51}$ Moreover, specific Rho inhibitors abrogate ERK2 activation in both $\alpha \mathrm{IIb} \beta 3$ isoforms (-Fig. 4), indicating that Rho GTPases such as Rac1 (- Fig. 2, inset) are involved in the signal transduction to ERK2.

These findings are in agreement with earlier reports by others, ${ }^{54}$ confirming that the Pro33 variant is characterized by enhanced signal transduction through $\alpha \operatorname{IIb} \beta 3$ from the platelet exterior to the platelet cytoskeleton.

\section{Impact of High Shear on Outside-in Signaling of Variant $\alpha$ llb $\beta 3$}

Pathological shear stress can modulate the activity of $\alpha$ IIb $\beta 3 .^{55}$ Consequently, it has been proposed that the integrin may also operate as a platelet mechanosensor and contribute to mechanotransduction. While such a function is very likely for GPIbIX-V ${ }^{16}$ it currently remains unproven for $\alpha$ IIb $\beta 3$. Regardless of this unresolved issue, it has been of interest to explore whether abnormal shear conditions have an impact on $\alpha$ IIb $\beta$ in relation to the HPA-1 polymorphism. Remarkably, adherent Pro33 platelets and $\alpha$ IIb $\beta 3$-transfected cells expressing the Pro33 (HPA-1b) variant were shown to have a higher adhesion activity upon exposure to increasing shear rates $(1,600$ per second), as compared with the Leu33 (HPA-a) isoform. ${ }^{45,48}$ In accordance with this observation, both tyrosine kinases, cSrc and FAK, exhibit a twofold higher phosphorylation activity in Pro33 than in Leu33 platelets, when exposed to abnormal shear conditions ${ }^{51,56}$ (- Fig. 5).

\section{Conclusions and Perspectives}

Platelets respond to a variety of activating and inhibitory stimuli, both of which may have a strong impact on whether or not an occluding thrombus will form. The versatility of platelet reactions to environmental conditions may also explain why the consequences of inhibiting specific platelet agonists can differ in physiological haemostasis and pathological thrombosis. ${ }^{57}$

The type of arterial vessel(s) involved, local dysfunction of endothelial cells, possibly in association with inflammatory processes, exposure of tissue factor, and/or subendothelial extracellular matrix proteins (such as highly reactive collagens) are important determinants that will enhance platelet thrombogenicity. For example, circulating tissue factor co-localizes at the site of a developing thrombus and contributes substantially to the recruitment and activation of circulating platelets through the generation of $\alpha-$ thrombin. ${ }^{58}$ Thus, the nature and extent of a vascular lesion may influence the amount and activity of tissue factor and, consequently, the extent and growth rate of a forming platelet-fibrin thrombus. Moreover, local increase in blood velocity with resulting increase in shear stress at sites of stenosed arteries will also influence platelet reactivity. At the apex of a severely occluded coronary artery, shear rates might exceed 50,000 per second. ${ }^{59,60}$ High shear stress may enhance platelet reactivity through the VWF-A1/GPIb-IX-V axis of platelet adhesion and activation, ${ }^{16,57}$ and possibly through $\alpha \operatorname{IIb} \beta 3$.

The aspects of platelet responses to vascular injury discussed here may be modified by genetic variations in the 

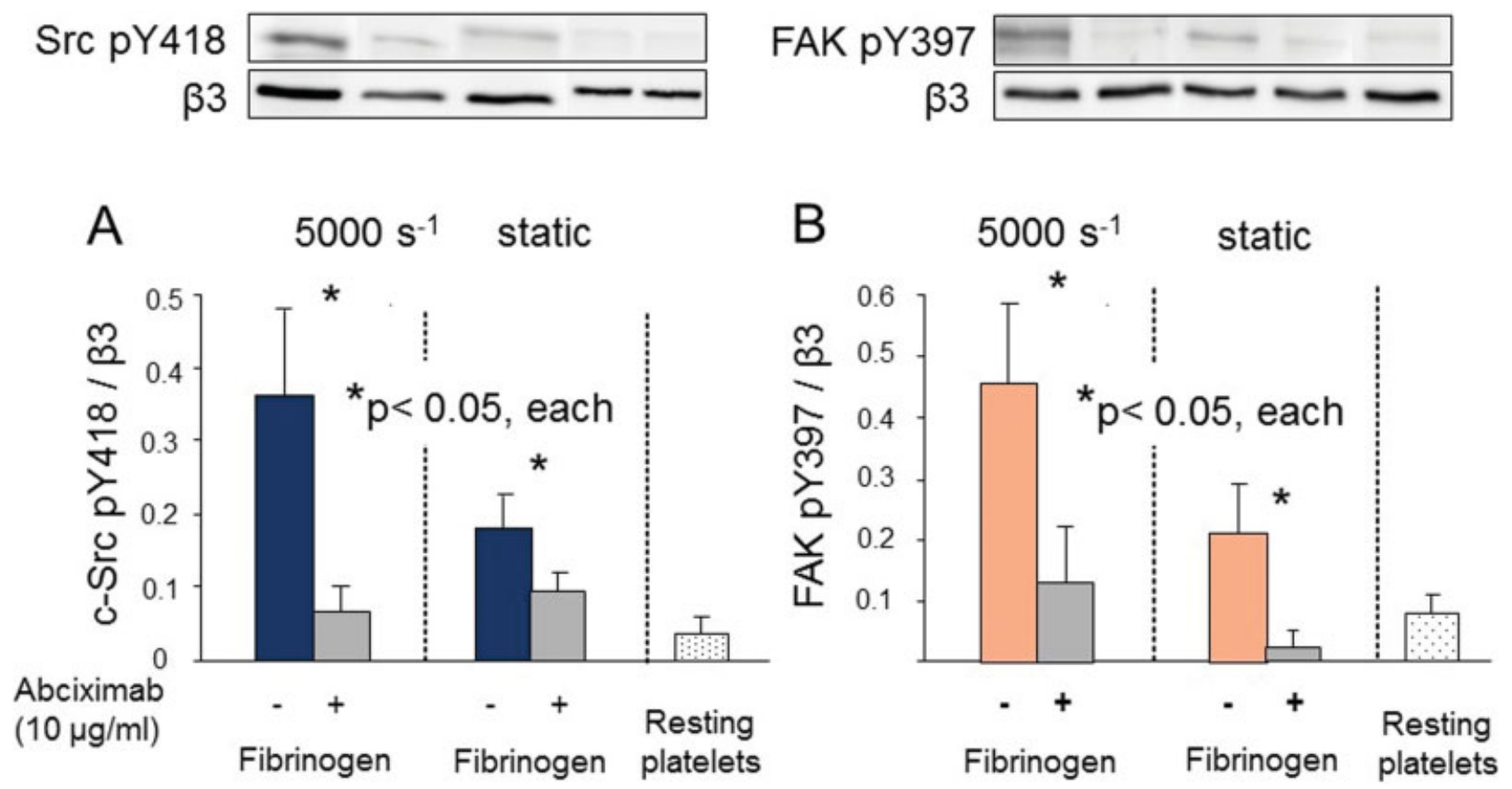

Fig. 5 Effect of high shear on platelet c-Src and FAK activity in comparison to static condition. Focal adhesion kinase (FAK) is a substrate of Src family kinases (SFKs) downstream of $\alpha$ llb $\beta 3$, forming SFK-FAK complexes within focal adhesions of platelets in response to ligand-induced integrin clustering. Upon activation of FAK by autophosphorylation at Tyr397, the SFK-FAK complexes induce phosphorylation of additional tyrosine residues in FAK that serve as 'docking sites' for downstream effectors. Washed human platelets incubated on fibrinogen are left under static conditions or exposed to shear rates of 500 or 5,000 per second, respectively, using a cone-plate viscometer. Specific phosphorylation of c-Src (pY418) and FAK (pY397) is determined by Western blotting and quantified densitometrically (see legend to - Fig. 3, except that $\beta 3$ is used as reference for quantitation). Both c-Src (A) and FAK (B) exhibit specific phosphorylation under static condition. Exposure of adherent platelets to a shear rate of 500 per second does not increase phosphorylation activities (not shown), whereas high shear rates (5,000 per second) induce an increase in c-Src pY418 and FAK pY397 activities. Under static and high shear conditions, Pro33 platelets (coloured columns) exhibit higher phosphorylation rates of both kinases than Leu33 platelets (light grey columns). By contrast to c-Src, in the absence of fibrinogen, platelets incubated over a BSA matrix and subsequently exposed to high shear (for up to 10 minutes) display a ninefold increase in pY397 activity in a time-dependent manner, as compared with static conditions. This observation indicates that FAK signaling can be induced by shear stress, whereas c-Src activation appears to be predominantly ligand dependent in adherent platelets both under static and high-shear conditions. Addition of abciximab inhibits c-Src and FAK signaling both under static and shear conditions. The blots are representative of five separate experiments in each setting. Experimental conditions: fibrinogen $(100 \mu \mathrm{g} / \mathrm{mL})$; incubation at $37^{\circ} \mathrm{C}$; adhesion time of 10 minutes; exposure time to shear of 2 minutes, unless otherwise indicated.

many proteins involved in adhesion, activation, and aggregation. This is especially true for platelet receptors, as illustrated by prothrombotic integrin variants such as Pro33 (HPA-1b) of $\alpha$ IIb $\beta 3$ or $\alpha 2$ 807TT of $\alpha 2 \beta 1 .{ }^{42,43,61,62}$ Search for polymorphisms in the corresponding genes, ${ }^{62}$ characterization of the genotype-phenotype relationship, ${ }^{50}$ and assessment of critical genotypes and their correlation to thrombotic events ${ }^{42,43,61}$ may prove useful in the identification and stratification of patients at risk and in the development of suitable targets for pharmacological intervention. ${ }^{57}$

\section{Disclosures}

The author states that he has no conflict of interest.

\section{Acknowledgment}

Work from the author's laboratory that is cited here was supported by grants from the German Research Council (DFG; Scha 358/1-1 to 3; 358/2-2; 358/3-1; Collaborative Research Center, SFB 612, Project B2). The author is grateful to members of his laboratory and to Drs. Z.M. Ruggeri, S.J. Shattil and H. Gohlke for fruitful discussions.
The Biological Medical Research Center, Heinrich Heine University, Düsseldorf, Germany, and the NRW Research School BioStruct 'Biological Structures in Molecular Medicine and Biotechnology' provided additional funding.

\section{References}

1 Offermanns S. Activation of platelet function through G proteincoupled receptors. Circ Res 2006;99(12):1293-1304

2 Scharf RE, Reimers H-J, Schneider W. Die Rolle der Kalziumionen bei der Regulation der Thrombozytenfunktion. Hamostaseologie 1981;1:3-37

3 Sambrano GR, Weiss EJ, Zheng YW, Huang W, Coughlin SR. Role of thrombin signalling in platelets in haemostasis and thrombosis. Nature 2001;413(6851):74-78

4 Mazzucato M, Pradella P, Cozzi MR, De Marco L, Ruggeri ZM. Sequential cytoplasmic calcium signals in a 2-stage platelet activation process induced by the glycoprotein Ib $\alpha$ mechanoreceptor. Blood 2002;100(08):2793-2800

5 Mazzucato M, Cozzi MR, Pradella P, Ruggeri ZM, De Marco L. Distinct roles of ADP receptors in von Willebrand factor-mediated platelet signaling and activation under high flow. Blood 2004;104 (10):3221-3227 
6 Mazzucato M, Cozzi MR, Battiston M, et al. Distinct spatiotemporal $\mathrm{Ca}^{2+}$ signaling elicited by integrin $\alpha 2 \beta 1$ and glycoprotein VI under flow. Blood 2009;114(13):2793-2801

7 Scharf RE. Drugs that affect platelet function. Semin Thromb Hemost 2012;38(08):865-883

8 Shattil SJ, Newman PJ. Integrins: dynamic scaffolds for adhesion and signaling in platelets. Blood 2004;104(06):1606-1615

9 Hynes RO. Integrins: bidirectional, allosteric signaling machines. Cell 2002;110(06):673-687

10 Shattil SJ, Kashiwagi H, Pampori N. Integrin signaling: the platelet paradigm. Blood 1998;91(08):2645-2657

11 Coller BS, Shattil SJ. The GPIIb/IIIa (integrin $\alpha$ IIb $\beta 3$ ) odyssey: a technology-driven saga of a receptor with twists, turns, and even a bend. Blood 2008;112(08):3011-3025

12 Coller BS. $\alpha$ IIb $\beta 3$ : structure and function. J Thromb Haemost 2015;13(Suppl 1):S17-S25

13 Durrant TN, van den Bosch MT, Hers I. Integrin $\alpha_{\mathrm{IIb}} \beta_{3}$ outside-in signaling. Blood 2017;130(14):1607-1619

14 Stegner D, Nieswandt B. Platelet receptor signaling in thrombus formation. J Mol Med (Berl) 2011;89(02):109-121

15 Zhang W, Deng W, Zhou L, et al. Identification of a juxtamembrane mechanosensitive domain in the platelet mechanosensor glycoprotein Ib-IX complex. Blood 2015;125(03):562-569

16 Ruggeri ZM, Mendolicchio GL. Interaction of von Willebrand factor with platelets and the vessel wall. Hamostaseologie 2015;35(03):211-224

17 Kasirer-Friede A, Ware J, Leng L, Marchese P, Ruggeri ZM, Shattil SJ. Lateral clustering of platelet GP Ib-IX complexes leads to upregulation of the adhesive function of integrin $\alpha$ IIb $\beta 3$. J Biol Chem 2002;277(14):11949-11956

18 Kasirer-Friede A, Cozzi MR, Mazzucato M, De Marco L, Ruggeri ZM, Shattil SJ. Signaling through GP Ib-IX-V activates $\alpha$ IIb $\beta 3$ independently of other receptors. Blood 2004;103(09):3403-3411

19 Watson SP, Asazuma N, Atkinson B, et al. The role of ITAM- and ITIM-coupled receptors in platelet activation by collagen. Thromb Haemost 2001;86(01):276-288

20 Clemetson JM, Polgar J, Magnenat E, Wells TN, Clemetson KJ. The platelet collagen receptor glycoprotein VI is a member of the immunoglobulin superfamily closely related to FcalphaR and the natural killer receptors. J Biol Chem 1999;274(41):29019-29024

21 Nieswandt B, Watson SP. Platelet-collagen interaction: is GPVI the central receptor? Blood 2003;102(02):449-461

22 Varga-Szabo D, Pleines I, Nieswandt B. Cell adhesion mechanisms in platelets. Arterioscler Thromb Vasc Biol 2008;28(03):403-412

23 Judd BA, Myung PS, Obergfell A, et al. Differential requirement for LAT and SLP-76 in GPVI versus T cell receptor signaling. J Exp Med 2002;195(06):705-717

24 Shattil SJ, Kim C, Ginsberg MH. The final steps of integrin activation: the end game. Nat Rev Mol Cell Biol 2010;11(04):288-300

25 Shattil SJ. Integrins and Src: dynamic duo of adhesion signaling. Trends Cell Biol 2005;15(08):399-403

$26 \mathrm{Wu} \mathrm{Y,} \mathrm{Span} \mathrm{LM,} \mathrm{Nygren} \mathrm{P,} \mathrm{et} \mathrm{al.} \mathrm{The} \mathrm{tyrosine} \mathrm{kinase} \mathrm{c-Src}$ specifically binds to the active integrin $\alpha \operatorname{Ilb} \beta 3$ to initiate outside-in signaling in platelets. J Biol Chem 2015;290(25): 15825-15834

27 Obergfell A, Eto K, Mocsai A, et al. Coordinate interactions of Csk, Src, and Syk kinases with $\alpha \operatorname{IIb} \beta 3$ initiate integrin signaling to the cytoskeleton. J Cell Biol 2002;157(02):265-275

28 Vidal C, Geny B, Melle J, Jandrot-Perrus M, Fontenay-Roupie M. Cdc42/Rac1-dependent activation of the p21-activated kinase (PAK) regulates human platelet lamellipodia spreading: implication of the cortical-actin binding protein cortactin. Blood 2002; 100(13):4462-4469

29 Schoenwaelder SM, Hughan SC, Boniface K, et al. RhoA sustains integrin $\alpha$ IIb $\beta 3$ adhesion contacts under high shear. J Biol Chem 2002;277(17):14738-14746

30 Law DA, DeGuzman FR, Heiser P, Ministri-Madrid K, Killeen N, Phillips DR. Integrin cytoplasmic tyrosine motif is required for outside-in $\alpha$ IIb $\beta 3$ signalling and platelet function. Nature 1999; 401(6755):808-811

31 Semple JW, Italiano JE Jr, Freedman J. Platelets and the immune continuum. Nat Rev Immunol 2011;11(04):264-274

32 Franco AT, Corken A, Ware J. Platelets at the interface of thrombosis, inflammation, and cancer. Blood 2015;126(05):582-588

33 Pluskota E, Woody NM, Szpak D, et al. Expression, activation, and function of integrin $\alpha \mathrm{M} \beta 2$ (Mac-1) on neutrophil-derived microparticles. Blood 2008;112(06):2327-2335

34 Duchene J, von Hundelshausen P. Platelet-derived chemokines in atherosclerosis. Hamostaseologie 2015;35(02):137-141

35 Martinod K, Wagner DD. Thrombosis: tangled up in NETs. Blood 2014;123(18):2768-2776

36 Demers M, Wong SL, Martinod K, et al. Priming of neutrophils toward NETosis promotes tumor growth. OncoImmunology 2016; 5(05):e1134073

37 Fuchs TA, Brill A, Duerschmied D, et al. Extracellular DNA traps promote thrombosis. Proc Natl Acad Sci U S A 2010;107(36): $15880-15885$

38 Jiménez-Alcázar M, Rangaswamy C, Panda R, et al. Host DNases prevent vascular occlusion by neutrophil extracellular traps. Science 2017;358(6367):1202-1206

39 Semeraro F, Ammollo CT, Morrissey JH, et al. Extracellular histones promote thrombin generation through platelet-dependent mechanisms: involvement of platelet TLR2 and TLR4. Blood 2011; 118(07):1952-1961

40 Carestia A, Rivadeneyra L, Romaniuk MA, Fondevila C, Negrotto S, Schattner M. Functional responses and molecular mechanisms involved in histone-mediated platelet activation. Thromb Haemost 2013;110(05):1035-1045

41 Zotz RB, Winkelmann BR, Nauck M, et al. Polymorphism of platelet membrane glycoprotein IIIa: human platelet antigen $1 \mathrm{~b}$ (HPA-1b/PlA2) is an inherited risk factor for premature myocardial infarction in coronary artery disease. Thromb Haemost 1998; 79(04):731-735

42 Zotz RB, Winkelmann BR, Müller C, Boehm BO, März W, Scharf RE. Association of polymorphisms of platelet membrane integrins $\alpha \operatorname{Ilb} \beta 3$ (HPA-1b/Pl) and $\alpha 2 \beta 1$ ( $\alpha 2$ 807TT) with premature myocardial infarction. J Thromb Haemost 2005;3(07):1522-1529

43 Zotz RB, Klein M, Dauben HP, Moser C, Gams E, Scharf RE. Prospective analysis after coronary-artery bypass grafting: platelet GP IIIa polymorphism (HPA-1b/PIA2) is a risk factor for bypass occlusion, myocardial infarction, and death. Thromb Haemost 2000;83(03):404-407

44 Scharf RE, Zotz RB. Blood platelets and myocardial infarction: do hyperactive platelets really exist? Transfus Med Hemother 2006; 33:189-199

45 Loncar R, Stoldt V, Hellmig S, Zotz RB, Mihalj M, Scharf RE. HPA-1 polymorphism of $\alpha$ IIb $\beta 3$ modulates platelet adhesion onto immobilized fibrinogen in an in-vitro flow system. Thromb J 2007;5:2

46 Loncar R, Zotz RB, Sucker C, Vodovnik A, Mihalj M, Scharf RE. Platelet adhesion onto immobilized fibrinogen under arterial and venous in-vitro flow conditions does not significantly differ between men and women. Thromb J 2007;5:5

47 El Khattouti A, Stoldt VR, Scharf RE. The HPA-1b (Pro33) isoform of platelet integrin $\alpha \operatorname{IIb} \beta 3$ is a prothrombotic variant: characterization by fluorescence resonance energy transfer. Blood 2010; 116:2018

48 El Khattouti A, Stoldt VR, Gyenes M, Huynh KC, Scharf RE. Variants of platelet integrin $\alpha$ IIb $\beta 3$ display different receptor activation. Blood 2011;118:1143

49 Scharf RE, Hasse M, Reiff E, Gyenes M, Stoldt VR. CD40 ligand (CD40L) increases thrombus stability and outside-in signaling through integrin $\alpha I I b \beta 3$. J Thromb Haemost 2009;(07, Suppl 2):060

50 Pagani G, Pereira JPV, Stoldt VR, Beck A, Scharf RE, Gohlke H. The human platelet antigen-1b (Pro ${ }^{33}$ ) variant of $\alpha_{I I b} \beta_{3}$ allosterically shifts the dynamic conformational equilibrium of this integrin toward the active state. J Biol Chem 2018;293(13):4830-4844 
51 Gyenes M, Hasse M, Stoldt VR, El-Khattouti A, Huynh KC, Scharf RE. Enhanced outside-in signaling through the prothrombotic Pro33 variant of integrin $\alpha$ IIb $\beta 3$ in adherent platelets under static and flow dynamic conditions. Blood 2011;118(21):2199

52 Gyenes M, Stoldt VR, Huynh KC, Scharf RE. The impact of shear stress on the interaction of human platelet integrin $\alpha$ IIb $\beta 3$ with fibrinogen. Blood 2012;120(21):2167

53 Ye F, Liu J, Winkler H, Taylor KA. Integrin $\alpha$ IIb $\beta 3$ in a membrane environment remains the same height after $\mathrm{Mn} 2+$ activation when observed by cryoelectron tomography. J Mol Biol 2008; 378(05):976-986

54 Vijayan KV, Liu Y, Sun W, Ito M, Bray PF. The Pro33 isoform of integrin $\beta 3$ enhances outside-in signaling in human platelets by regulating the activation of serine/threonine phosphatases. J Biol Chem 2005;280(23):21756-21762

55 Feng S, Lu X, Reséndiz JC, Kroll MH. Pathological shear stress directly regulates platelet $\alpha \mathrm{IIb} \beta 3$ signaling. Am J Physiol Cell Physiol 2006;291(06):C1346-C1354

56 Gyenes M, Stoldt VR, Huynh KC, Scharf RE. Impact of the Leu33Pro polymorphism of $\alpha$ IIb $\beta 3$ on integrin-ligand interaction under abnormally high shear conditions. Blood 2014;124(21):4156
57 Ruggeri ZM. Platelets in atherothrombosis. Nat Med 2002;8(11): 1227-1234

58 Balasubramanian V, Grabowski E, Bini A, Nemerson Y. Platelets, circulating tissue factor, and fibrin colocalize in ex vivo thrombi: real-time fluorescence images of thrombus formation and propagation under defined flow conditions. Blood 2002;100(08):2787-2792

59 Bluestein D, Niu L, Schoephoerster RT, Dewanjee MK. Fluid mechanics of arterial stenosis: relationship to the development of mural thrombus. Ann Biomed Eng 1997;25(02):344-356

60 Strony J, Beaudoin A, Brands D, Adelman B. Analysis of shear stress and hemodynamic factors in a model of coronary artery stenosis and thrombosis. Am J Physiol 1993;265(5, Pt 2):H1787-H1796

61 Bray PF. Platelet glycoprotein polymorphisms as risk factors for thrombosis. Curr Opin Hematol 2000;7(05):284-289

62 Kunicki TJ, Ruggeri ZM. Platelet collagen receptors and risk prediction in stroke and coronary artery disease. Circulation 2001;104(13):1451-1453

63 Aslan JE, McCarty OJ. Rho GTPases in platelet function. J Thromb Haemost 2013;11(01):35-46

64 Huveneers S, Danen EH. Adhesion signaling - crosstalk between integrins, Src and Rho. J Cell Sci 2009;122(Pt 8):1059-1069 